\title{
INVESTIGATION OF LARGE SGALE USE OF RADIOACTIVE KRYPTON-85 FOR LEAK DETEGTION IN THE SATURN SPACE VEHICLE
}

\author{
L. E. BROWNELL, M. A. FARVAR, G. L. GYOREY and M. YORK \\ Chemical and Metallurgical Engineering and Nuclear Engineering Departments, \\ University of Michigan, Ann Arbor, Michigan, USA
}

Received 28 April 1965

\begin{abstract}
A major problem in space flight has been leakage of fluids and gases and is particularly serious at launching. Comparatively small leaks of propellant and/or oxidizer can cause disasterous explosions. The emphasis on the initial studies reported in this article has been the development of an improved method for leak detection during factory test and checkout prior to launching and space flight. However, the long-range objective of a versatile leak detection system that could be used in space, during launching, as well as during static testing, was kept in view. A leak detection technique was developed based on the use of $\mathrm{Kr}^{85}$ as a radiotracer. This technique is described and is believed to be more versatile than any other. Krypton has sufficient solubility to be used as a tracer in all liquids tested, except hydrogen. Leakage rates can be determined with greater precision in the order of 0.005 SCIM (Standard Cubic Inches per Minute) than by any other methods. Because of safety and ease of use, radinkrypton shows great promise for many applications.
\end{abstract}

\section{METHODS OF LEAK DETECTION}

Since early in 1962, research work has been in progress at the University of Michigan on the applicability of radiotracers to the problem of leak detection in space vehicles. The work has been carried out with the support of the National Aeronautics and Space Administration, and is aimed specifically at the Saturn system shown in fig. 1. Saturn stages 1 and 2 will be the powerful boosters that launch the Apollo vehicle planned for the first U.S. manned space-vehicle flight to the moon.

One look at the business end of a complex space vehicle, such as the Saturn with its eight engines, immediately gives one a feeling for the immensity of the task of leak testing such a system. The complex piping and connections involved in the fuel, oxidizer, and various hydraulic systems must be tested and repaired by men while standing on scaffolding several stories high and while crawling through the interior of the vehicle. Fig. 2 shows engineers and technicians working on the fifth Saturn vehicle (SA-5) booster in the Marshall Space Flight Center's Manufacturing Engineering Division. Saturn SA-5 is the first of the Saturn I Block II configuration. This view shows six of the 1.5 million pound thrust booster's eight engines (NASA-Marshall photo 2-2140-1). Most of the more common methods of leak testing have not been found practical. At the present time, the methods most used in the leak testing of the Saturn vehicle at the George C. Marshall Space Flight Center in Huntsville, Alabama, are the following:

(1) Audio detection using the human ear.

(2) Application of liquid solution to a joint and visual observation of bubble formation.

(3) Use of halogen leak detectors.

In all of these methods the system under test is pressurized. This is the preferred condition for testing since it tends to duplicate the normal operating conditions. The first two methods are applicable only to relatively large leaks and rely too much on human patience and judgment. The third method listed relies on the increase in positive ion emission from a heated platinum surface in the presence of halides. The system to be tested is pressurized with a mixture of air and halogen gas such as freon-12. Joints and connections are examined for leakage by holding a probe in their vicinity which sucks in air and passes it over a platinum filament operated at about $1600^{\circ} \mathrm{F}$. The presence of a sufficiently high concentration of halogen gas then produces a visible or audible signal. Leaks of the order of $3.66 \times 10^{-4}$ SCIM (Standard Cubic Inches per Minute) $\left(10^{-4} \mathrm{cc} / \mathrm{sec}\right.$ or 0.05 in. $3 /$ day $)$ can be detected under practical test conditions using commercially available halogen detectors. 


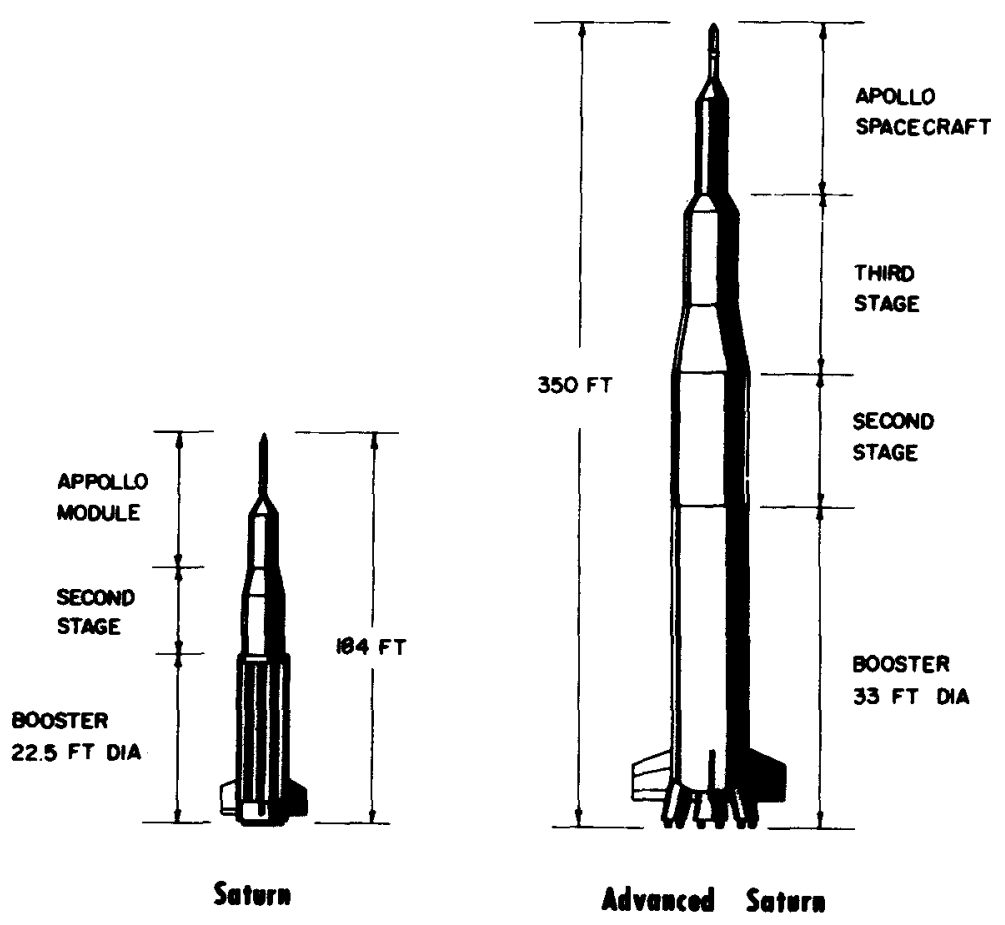

Fig. 1a. Scale sketches of Saturn Apollo and advanced Saturn space vehicles.

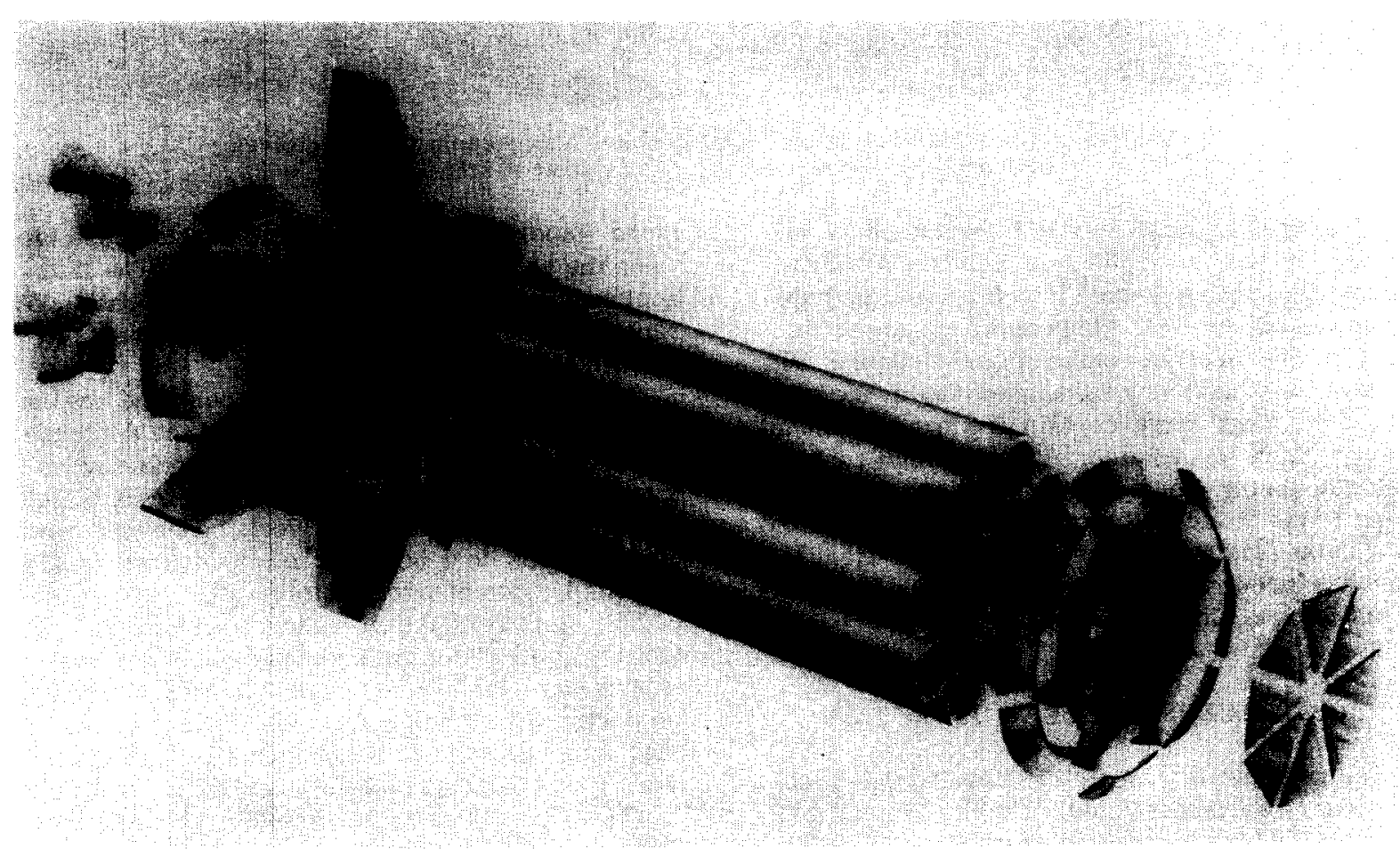

Fig. 1b. Exploded view of Saturn space vehicle. 


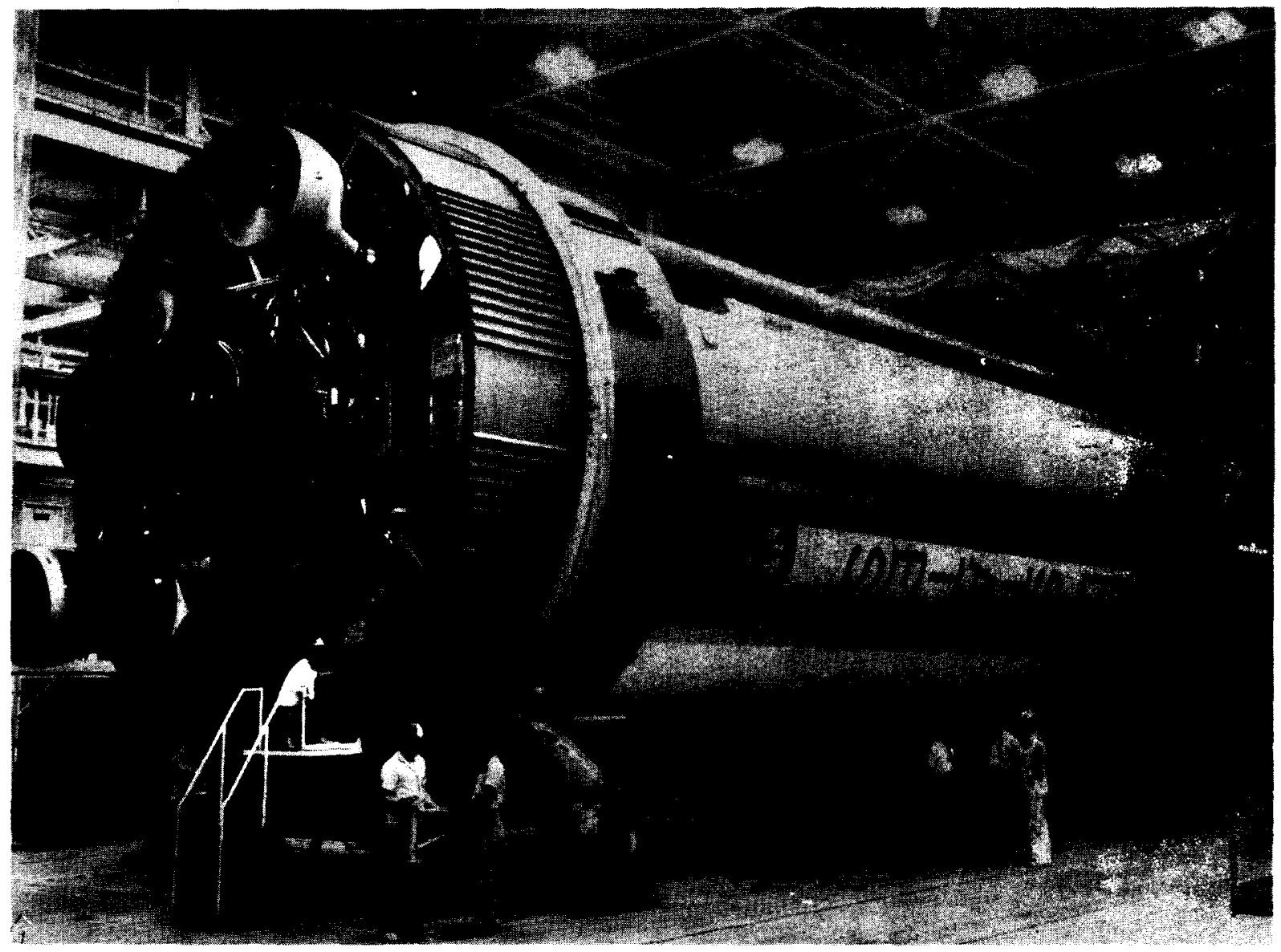

Fig. 2. Saturn SA-5 in Marshall Space Flight Center's Manufacturing and Engineering Division, Huntsville, Alabama (NASA-photo 2-2140-1).

Although the sensitivity of this method is sufficient, it has a number of serious disadvantages. The method cannot be used when the vehicle is fueled, or even when there is any possibility of the presence of explosive vapors. To achieve the sensitivity mentioned above, the system under test must contain freon as much as $10 \%$ or more by volume. At these high concentrations, being considerably heavier than air, freon tends to accumulate at low spots and may give false instrument readings long after the leak has been repaired. Furthermore, the freon diffuses quite slowly into long pipes.

\section{RADIOTRACERS FOR LEAK DETECTION}

The applicability of radiotracers to this problem has been investigated. The long-term goal was to supplement present methods of leak detection where they are inadequate, and perhaps more important, to make leak detection possible when the vehicle is fueled or in flight. The latter applications would require the incorporation of radiotracers into the propellants and various hydraulic fluids used in the system.

The initial phase of the work centered on the selection of a suitable tracer, and the determination of the sensitivity of the method using various tracer concentrations and simple radiation detection instrumentation. Work concerned with the solubility and behavior of the tracer in the various liquids of interest followed.

The requirements considered led to the selection of $\mathrm{Kr}^{85}$ as the most versatile and useful tracer material. $\mathrm{Kr} 85$ is one of the few fission products with a half-life over 10 years and is readily available in large quantities. Being a noble gas and principally a beta-particle emitter $(99.6 \%)$, its maximum permissible concentration (MPC) in air from the point of view of health physics is one of the highest. The beta-particle 
radiation emitted by $\mathrm{Kr} 85$ has a maximum energy of $0.69 \mathrm{MeV}$ and is attenuated by air, at nor mal temperature and pressure, with a half-value thickness of about $20 \mathrm{~cm}$. This means that the magnitude of the beta flux at a point is indicative of the tracer concentration in the near vicinity. $\mathrm{Kr}^{85}$ is relatively easy to detect in low concentrations. A thin walled $\left(30 \mathrm{mg} / \mathrm{cm}^{2}\right)$ Geiger tube of the type commonly used with portable survey meters (such as the Victoreen 1B85 or the Anton 112 with an approximately $2 \mathrm{~cm}$ diameter by $7 \mathrm{~cm}$ long sensitive volume) will give a count rate of the order of 500 counts per minute in an effectively infinite homogeneous cloud with a concentration of $10^{-5} \mu \mathrm{C} / \mathrm{cc}$. A sphere of $1 \mathrm{~m}$ radius appears for all practical purposes as an infinite cloud to a detector placed at its center.

The $0.52 \mathrm{MeV}$ gamma photon emitted by $\mathrm{Kr} 85$ in about $0.35 \%$ of the decays presents a background problem when curie amounts and greater of this tracer are used. The gamma dose rate at 1 meter from 1 curie of unshielded $\mathrm{Kr} 85$ is approximately $1 \mathrm{mR} / \mathrm{hr}$. This gamma field produces in a Geiger tube of the type mentioned previously of the order of 3000 counts per minute, whereas the inherent background count rate of this tube is only about 40 counts per minute.

\section{PROCEDURE FOR USE OF Kr85 IN LOCAT- ING LEAKS DURING STATIC TESTING OF SPACE VEHICLES}

After the portion of the vessel or lines to be tested are filled with the $\mathrm{N}-\mathrm{Kr}^{85}$ mixture, surveys for leaks can be made with either GeigerMüller (G-M) tubes or solid state detectors.

The G-M tube and a survey meter provide a portable and compact detection system that is well adapted to the detection of leaks in space vehicles. A portable G-M tube survey meter with earphones may be used so an audio as well as visual detection of leak can be made. Since the count rate of a G-M tube is high, a leak can be located with this system in a matter of seconds.

Fig. 3 shows the count rate of a metallicwalled $G-M$ tube vs. distance from a 0.08 in. 3 / min leak of $0.4 \mu \mathrm{C} / \mathrm{cc}$ of $\mathrm{Kr} 85$ and one can readily see that a leak of this magnitude can be located by the $\mathrm{G}-\mathrm{M}$ tube system at distances over one foot.

The maximum detection distance from a 0.08 SCIM (std. in. $3 / \mathrm{min}$ ) leak of $0.04 \mu \mathrm{C} / \mathrm{cc} \mathrm{Kr} 85$ is 10 in. for the Victoreen $1 B 85 \mathrm{G}-\mathrm{M}$ tube. It should be noted that with $0.4 \mu \mathrm{C} / \mathrm{cc} \mathrm{Kr}^{85}$ leak of this same magnitude, see fig. 3 , the maximum detec-

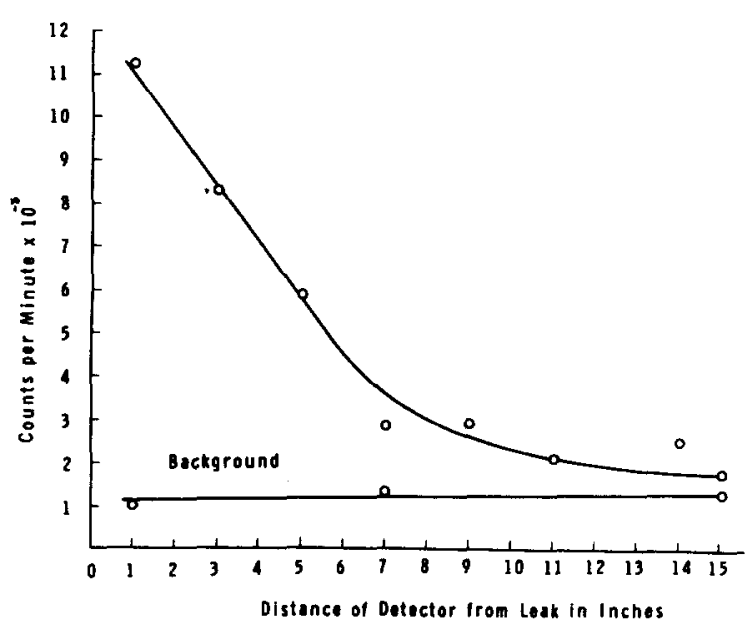

Fig. 3. Metal walled G-M tube data. Count rate is distance from a 0.08 in. $3 / \mathrm{min}$ leak of $0.4 \mu \mathrm{C} / \mathrm{cc}$ of $\mathrm{Kr}^{85}$ (axis of G-M tube perpendicular to leali axis: all measurements taken under an exhaust hood).

tion distance is about 12 in. This shows that changes in the $\mathrm{Kr} 85$ concentration do not strongly affect the sensitivity of the detector.

The procedure to be used with this type of instrument is to hold the G-M tube near the vessel of pipe lines (within a foot and better within a few inches) and move along the surface slowly watching the meter and/or listening with the

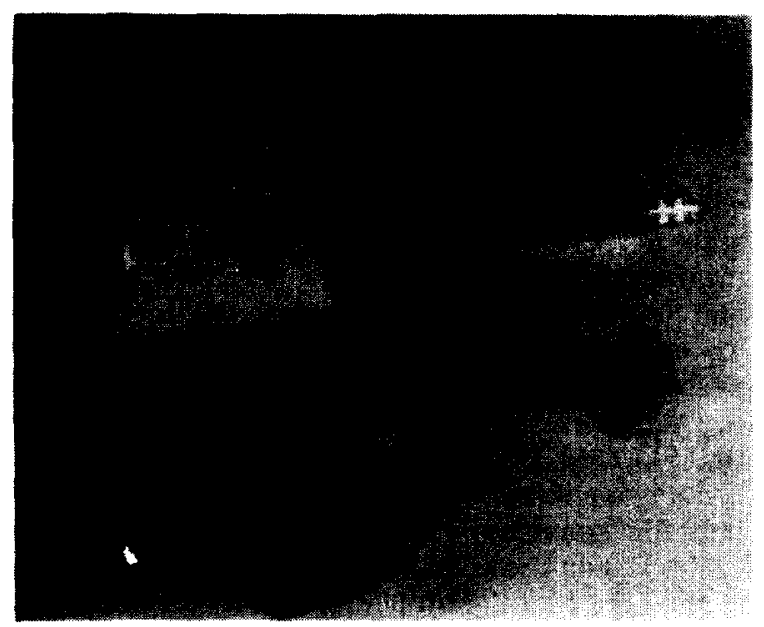

Fig. 4. Photograph of solid-state detection apparatus. Preamplifier (Solid State Radiations Inc., model 101) and power supply for solid-state detectors shown in plastic boxes. The large (upper) and small (lower) surface area silicon surface barrier detection are Molechem Inc., Models SSD-A-200-30 and SSD-D-200-40. 


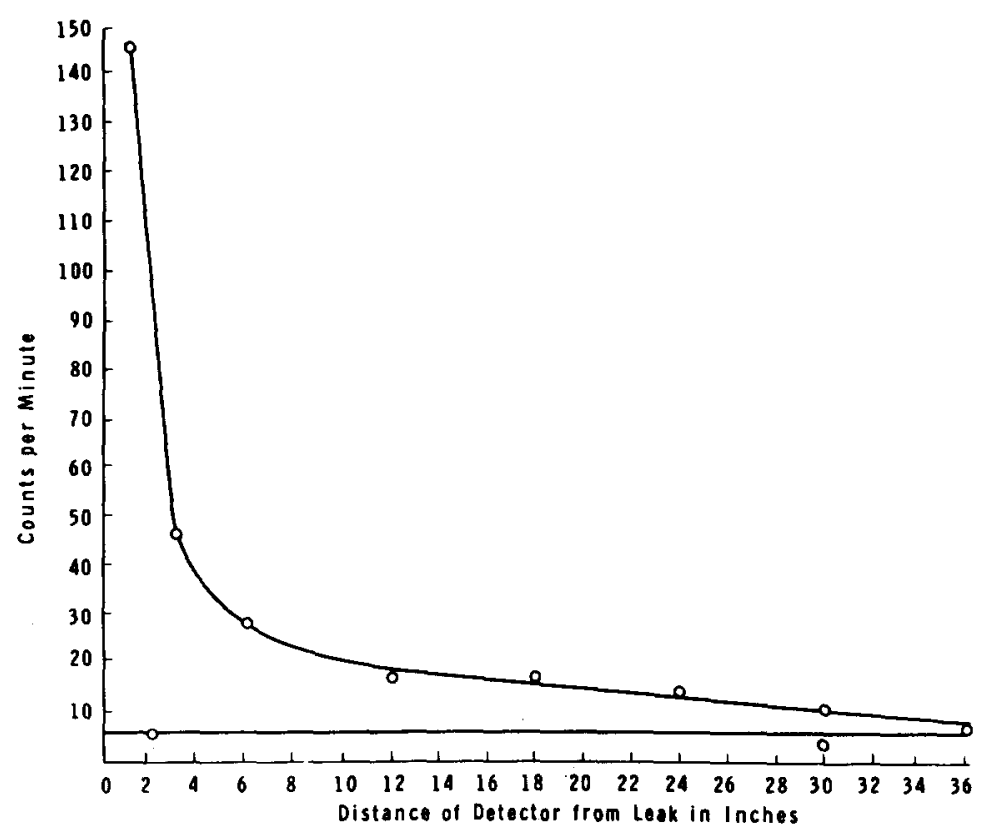

Fig. 5. Semiconductor radiation detector data. Count rate vs. distance from a 0.08 in. $3 / \mathrm{min}$ leak of $0.4 \mu \mathrm{C} / \mathrm{cc}$ of $\mathrm{Kr}^{85}$ with $2 \mathrm{~cm}^{2}$ surface area solid-state detector (surface of detector perpendicular to leak axis; all measurements taken under an exhaust hood).

earphones. With a leak of 0.08 SCIM of $0.04 \mu \mathrm{C}$ $\mathrm{Kr} 85$ the count rate will jump from $1200 \mathrm{cpm}$ (counts per minute) to $2300 \mathrm{cpm}$ when the G-M tube is 10 inches from the leak. With such significant increases in count rates one can easily see the ease with which this instrument can be used to detect leaks.

Alternatively, one can make leak surveys with a solid state detector and preamplifier system as shown in fig. 4. The preamplifier is the thin rectangular box to the right in fig. 4 . The solid state detector conveniently connects to the end of this probe type preamplifier and the complete unit then makes a handy surveying instrument. To compare this instrument with the G-M tube system the count rate vs. distance from a 0.08 in. $3 / \mathrm{min}$ leak of $0.4 \mu \mathrm{C} / \mathrm{cc}$ of $\mathrm{Kr}^{85}$ is shown in fig. 5. This particular plot was made with a $2 \mathrm{~cm}^{2}$ area solid-state detector. It can be seen that the sensitivity of the solid-state detector is greater than the G-M tube. This is primarily due to the fact that the solid-state detector is almost insensitive to the gamma radiation from the $\mathrm{Kr}{ }^{85}$, whereas the $\mathrm{G}-\mathrm{M}$ tubes are very sensitive to gammas. The presence of gammas is to be expected because of the amount of $\mathrm{Kr} 85$ inside the vessel being tested. This was simulated in our experiments by conducting our measurements near our storage tanks of $\mathrm{Kr} 85$.

With a solid-state detector, leaks can be detected from distance of up to two feet. Sensitivities of down to 0.009 SCIM using $0.4 \mu \mathrm{C} \mathrm{Kr} 85$ were obtained.

Although the sensitivity of the solid-state detector is much greater than the G-M tube, its output, that is cpm, is low. Thus, when using solid-state detectors to locate leaks, the detector must be moved much slower than when using the G-M tube.

In either case, the G-M or solid-state detectors, care should be used when handling the instruments. Rough use and jarring should be avoided as both of these devices are sensitive instruments and end shock may cause malfunction.

\section{MEASUREMENT OF LEAKAGE RATES WITH RADIOKRYPTON}

$\mathrm{Kr} 85$ can be used to make precise measurements of leakage rates. In this regard, the radioisotope technique is superior to any other technique and should have great usefulness in 


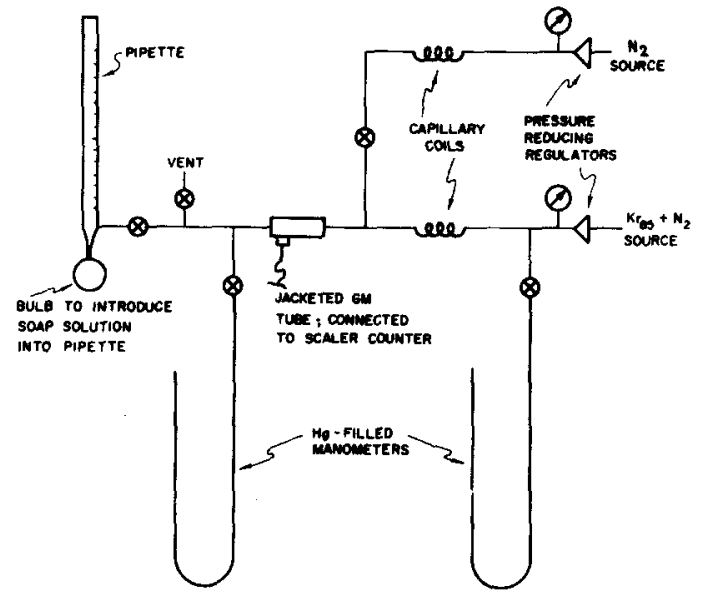

Fig. 6. Experimental apparatus for demonstration of low rate leak detection technique.

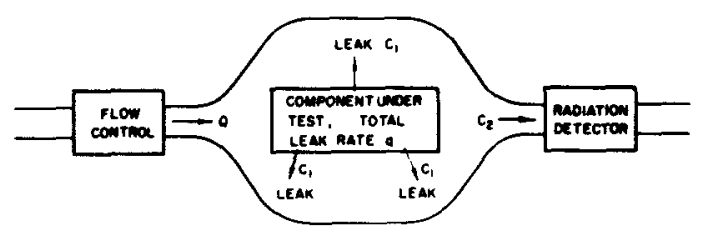

Fig. 7. Diagram for measurement of leakage rate using the $\mathrm{Kr}^{85}$ technique and once-through count of leaking fluid.

determining whether or not small leaks found in space vehicles during static testing are less than the maximum permissible leakage rates where the specifications for the joints under test provide for a limited leakage.

The principle of the slope measurement method with $\mathrm{Kr} 85$ is illustrated in fig. 6 .

For measuring small flow rates (leaks), $Q$ is known and $q$ is unknown. The component or vessel to be tested is filled with fluid containing $\mathrm{Kr}^{85}$ concentration $C_{1}$. Then inert fluid at a known flow rate $Q$, is passed around the vessel or component in a jacket or manifold, as shown in fig. 7. The concentration in the diluting stream will then be a direct measure of the total leak rate $q$. Note, it can be shown that

$$
q=Q \frac{C_{2}}{C_{1}}
$$

and $Q$ and $C_{1}$ are known and $C_{2}$ is measured.

The measurement is only limited by the minimum concentration that the radiation detector can measure with statistical significance above the background count rate.

An interesting variation can be introduced to

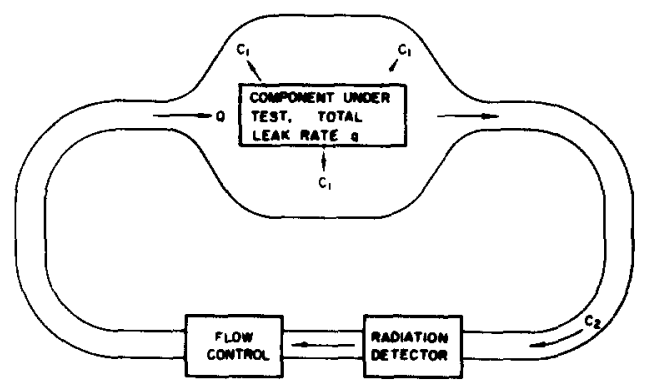

Fig. 8. Diagram for measurement of leakage rate using $\mathrm{Kr} 85$ technique and accumulation of leaking fluid.

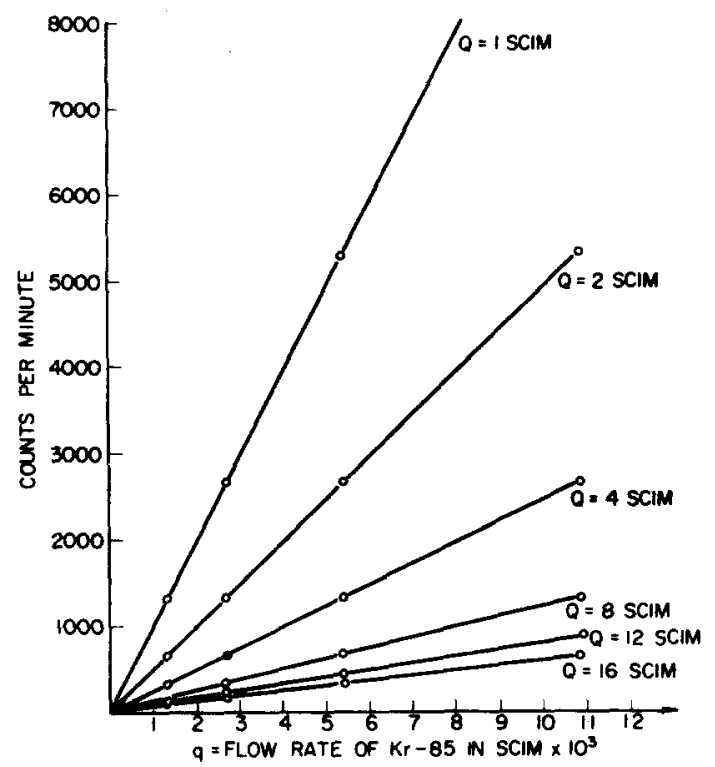

Fig. 9. Count rate vs. leakage rate $q$ of test gas for various flow rates $Q$ of $\mathrm{N}_{2}$ gas.

circumvent the limitation mentioned above. Instead of using the once-through system of fig. 7, the manifold surrounding the leak is closed, and the fluid is circulated through it and the detector. Fig. 8 shows this arrangement. In this case the leaking fluid is allowed to accumulate in the manifold, the concentration observed by the detector will be increasing in time and will at any time be an indication of the total leakage up to that time. The relationship is

$$
c_{2}=\frac{c_{1} q}{V} t,
$$

therefore

$$
q=\frac{C_{2} V}{C_{1} t}
$$




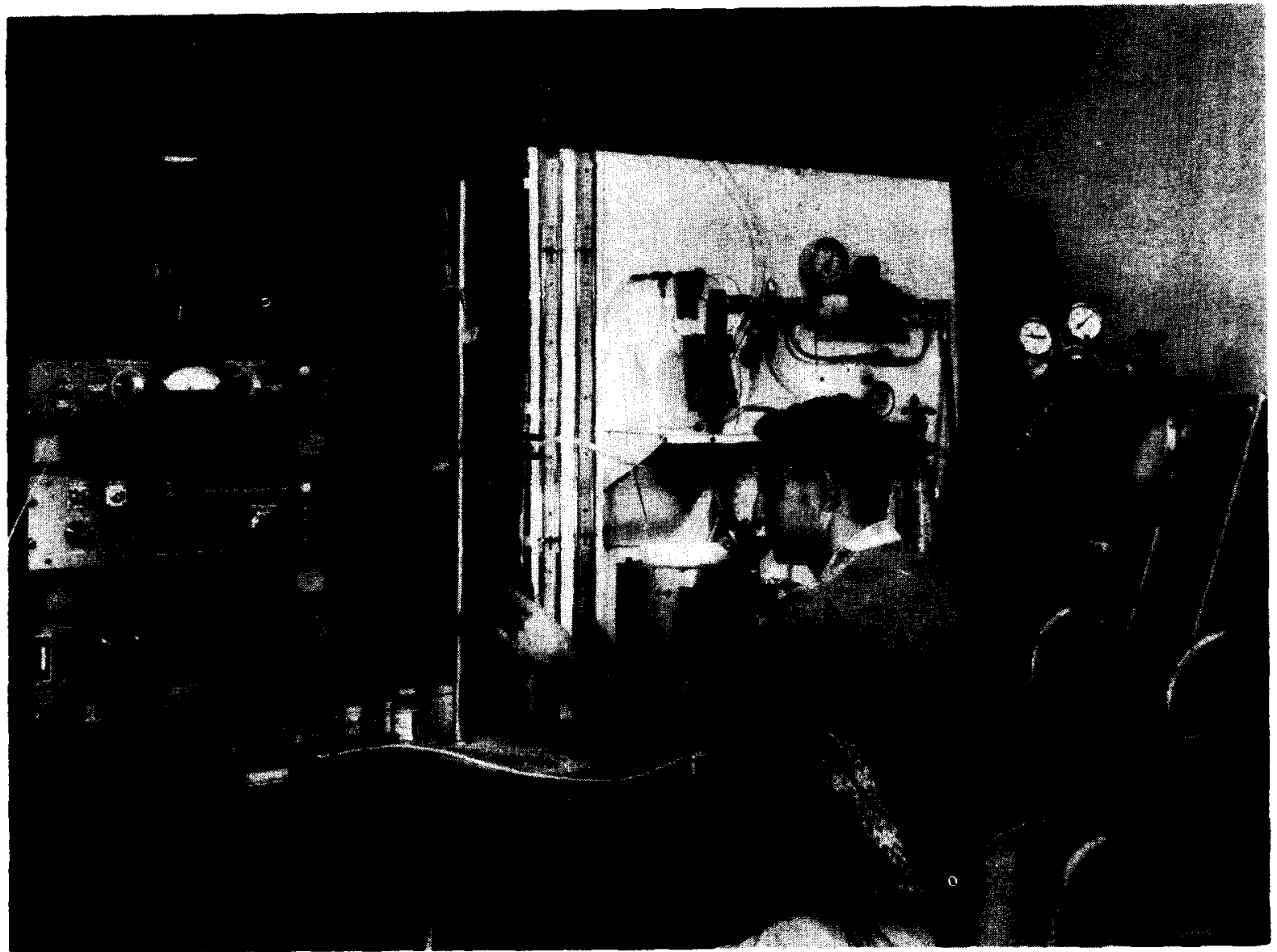

Fig. 10. Photograph of apparatus for gas flow rate calibration with M. A. Farvar in foreground.

where $t$ is the time and $V$ is the total volume of the manifold.

Once calibrated the system is remarkably simple to use. For a manifold a plastic envelope is used and can be sealed around any shape or combination of equipment which is smaller than the internal volume of the plastic manifold. Inert gas such as $\mathrm{N}_{2}$ is then pumped through and count rates taken. For example, using a jacketed G-M tube model 10315 by Radiation Counter Laboratories, the following calibration was made, see fig. 9 .

Thus, to determine the leak rate one need only read $Q$ from a flow meter, and note the count rate. Then by simply looking at the calibration curves such as fig. 9 , the leak rate can be immediately found. Using the G-M tube no. 10315 the leak rates can easily be found as low as 0.005 SCIM with no difficulty. Improvement of the sensitivity of the G-M tube can reduce this amount still more.

Data for the calibration curve shown in fig. 9 were obtained with apparatus for gas flow rate measurements shown in fig. 10 .

\section{CONCLUSION}

The radiokrypton tracer technique has been established as the most sensitive of any technique for measuring leakage rates. The measurement of leakage rates as low as 0.005 SCIM have been demonstrated and are easily performed with inexpensive G-M tube apparatus. Sensitivities of two or more orders of magnitude are obtainable with more sophisticated apparatus. Detection of leaks from leaking components has been demonstrated at distances up to $3 \mathrm{ft}$ from the source of the leak using solid-state detectors and at distance up to 12 in. using thin-wall Geiger-tube detectors. Since making these measurements in 1962 numerous improvements have been made in the state of the art of solid-state 
detection equipment with improvements in both range and sensitivity.

The research studies conducted for NASA contract NAS8-2579 have demonstrated that the radiotracer technique is probably the most versatile of all leak detection techniques and can be of extreme usefulness in the inspection and assurance of reliability of space vehicles and space vehicle components. Vapor-liquid equilibrium measurements have shown that krypton is infinitely soluble in liquid oxygen and extremely soluble in hydrocarbon fuels and fluids. A general correlation for prediction of the solubility of krypton in other liquids has been demonstrated. Only one liquid, hydrogen, has been found of many tested which does not have sufficient solubility for krypton to permit radiokrypton being used for leak detection purposes. The liquid hydrogen cryostat used in the krypton-liquid hydrogen studies might be used to explore the use of tritium, $\mathrm{H}_{3}$, as a radiotracer for locating liquid hydrogen leaks. A comment is made here for those who are not experienced in the extent of hazard in working with various radioisotopes and to point out the safety of testing with radiokrypton.

From the consideration of safety, radiokrypton tracer used in leak detection is much safer than such common items as gasoline, exhaust gases from engines, high-voltage circuits, drycleaning fluids such as carbon tetrachloride and such common missile items as LOX, liquid oxygen. Radiokrypton shows promise for extensive use without producing an injury to the operating personnel. However, because $\mathrm{Kr} 85$ is an artificial radioisotope it falls under the controls established by the U.S. Atomic Energy Commission and in the U.S.A. must be handled according to the established regulations of this Commission. More extensive use of this versatile tool is anticipated. 